\title{
Crescimento e respostas enzimáticas do feijoeiro caupi sob estresse hídrico e nematoide de galhas
}

Carmem C. M. de Sousa ${ }^{1}$, Elvira M. R. Pedrosa ${ }^{2}$, Mario M. Rolim ${ }^{3}$, Ronaldo A. de Oliveira Filho ${ }^{4}$, Marcela A. L. M. de Souza ${ }^{5}$ \& João V. Pereira Filho ${ }^{6}$

\section{Palavras-chave:}

Vigna unguiculata Meloidogyne incognita enzimas oxidativas

\begin{abstract}
R E S U M O
Considerando a importância do feijoeiro caupi no Nordeste brasileiro, o presente estudo teve, por objetivo, avaliar o crescimento e os aspectos bioquímicos do cultivar EPACE-10 submetido a estresse hídrico e parasitismo de Meloidogyne incognita em condições de casa de vegetação. O delineamento adotado foi de blocos ao acaso em esquema fatorial 2 (com e sem nematoide) $\times 2$ (com e sem estresse hídrico), com seis repetições. O nível de estresse hídrico aplicado ( $50 \%$ da capacidade do campo) diminuiu a reprodução do nematoide; entretanto, o desenvolvimento das plantas aferido pelas biomassas frescas e secas do caule e folhas, número de folhas, índice de área foliar, altura da planta e pela biomassa fresca da raiz, não foi afetado pelo estresse hídrico aplicado. As respostas das enzimas oxidativas ao estresse hídrico e parasitismo de $M$. incognita foram variáveis. A peroxidase não foi afetada, a catálase foi diminuída pelo parasitismo do nematoide, a ascorbato peroxidade diminuída pelo estresse hídrico e a polifenoloxidase diminuída pelo estresse hídrico e pelo parasitismo de M. incognita.
\end{abstract}

\section{Key words:}

Vigna unguiculata

Meloidogyne incognita

oxidative enzymes

\section{Growth and enzymatic responses of cowpea under water stress and root-knot nematode}

\begin{abstract}
A B S T R A C T
Considering the importance of cowpea beans in the Northeast of Brazil, the present study aimed to evaluate growing and biochemical aspects of cultivar EPACE-10 subjected to water stress and parasitism of Meloidogyne incognita under greenhouse conditions. The design was a randomized block design in a factorial 2 (with and without nematode) $\times 2$ (with and without water stress), with six replications. The level of applied water stress $(50 \%$ of the field capacity) reduced the nematode reproduction. However, plant growth measured by fresh and dry biomass of stems and leaves, leaf number, leaf area index, plant height and fresh root biomass was not affected by water stress applied. The responses to water stress and oxidative enzymes and parasitism of $M$. incognita were variable. Peroxidase was not affected; catalase was decreased by nematode parasitism, ascorbate peroxidase decreased by water stress and polyphenoloxidase decreased by water stress and parasitism of M. incognita.
\end{abstract}

Protocolo 006.14 - 08/01/2014 • Aprovado em 26/09/2014 • Publicado em 01/02/2015

${ }^{1}$ INOVAGRI, Fortaleza, CE. E-mail: crismareco@hotmail.com (Autora correspondente)

${ }^{2}$ UFRPE, Recife, PE. E-mail: elvira.pedrosa@dtr.ufrpe.br

${ }^{3}$ UFRPE, Recife, PE. E-mail: rolim@dtr.ufrpe.br

${ }^{4}$ UFRPE, Recife, PE. E-mail: ronaldoalvesfoto@hotmail.com

${ }^{5}$ UFRPE, Recife, PE. E-mail: marcelandrade.lima@hotmail.com

${ }^{6}$ DEA/UFC, Fortaleza, CE. E-mail: joao_valdenor@hotmail.com 


\section{INTRODUÇÃo}

O feijão caupi (Vigna ungüiculada (L.) Walp.) é o alimento básico das populações, exercendo importante função social no suprimento das necessidades nutricionais das pessoas, além de desempenhar papel fundamental na composição da produção agrícola brasileira, particularmente das regiões Norte e Nordeste. Por outro lado, a maneira como a planta responde ao déficit hídrico é bastante complexa de vez que afeta praticamente todos os aspectos de crescimento, incluindo modificações anatômicas, morfológicas, fisiológicas e bioquímicas (Mendes et al., 2007).

Em 60\% das áreas cultivadas do Nordeste brasileiro o feijoeiro caupi é considerado planta rústica, adaptável aos diferentes climas e solos, em virtude das condições climáticas desta região serem desfavoráveis ao cultivo sequeiro do feijoeiro comum (Phaseolus vulgaris L.). Além do mais, o feijoeiro caupi apresenta boa capacidade de adaptação à seca, embora esta capacidade varie entre os cultivares e os estádios de desenvolvimento (Leite \& Virgens Filho, 2004).

O estresse desempenha papel importante na determinação de como o solo limita a distribuição de espécies vegetais. Por isso, o conhecimento da resposta da planta ao déficit hídrico e da relação entre consumo de água e produtividade, é fundamental para o manejo adequado da cultura visando à alta produtividade (Nascimento et al., 2004).

Muitas vezes, as respostas dos vegetais à deficiência hídrica incluem alterações bioquímicas em nível celular, como exemplo as peroxidases, mudanças nas proporções de aminoácidos e aumentos frequentes na concentração de prolina são ocasionados por distúrbios no metabolismo das proteínase, possivelmente para manutenção do potencial hídrico da folha, que aumenta o teor deste aminoácido, para ajuste osmótico e defesa da planta à desidratação. Contudo, as respostas das plantas podem diferir entre espécies, cultivares, tecidos analisados, duração e intensidade do estresse (Campos et al., 2004).

Em relação aos componentes bióticos, os nematoides, em particular os nematoides das galhas (Meloidogyne sp. Goeldi), constituem um dos problemas fitossanitários mais importantes na cultura do feijoeiro caupi devido à ampla gama de hospedeiros e à alta capacidade de sobrevivência no solo. Quando presentes em altas densidades populacionais, especialmente em solos arenosos, esses parasitos afetam drasticamente a fisiologia da planta hospedeira prejudicando a absorção e o transporte de água e nutrientes. Praticado na maioria dos casos, como agricultura de subsistência, com o uso de insumos modernos e nematicidas, o manejo de Meloidogyne spp. em caupi depende sobretudo da utilização de variedades resistentes (Silva et al., 2007; Wanderley et al., 2007).

Considerando a importância do feijoeiro caupi para a população de baixa renda e a necessidade de elucidar componentes do comportamento de cultivares desenvolvidos para o plantio em regime de sequeiro na região Nordeste frente às limitações hídricas impostas, o objetivo deste estudo foi avaliar o crescimento e os aspectos bioquímicos do feijoeiro caupi submetido a estresse hídrico e o parasitismo de $M$. incognita em condições de casa de vegetação.

\section{MATERIAl E MÉtodos}

O experimento foi conduzido em casa de vegetação pertencente à Universidade Federal Rural de Pernambuco, localizada no Município de Recife, Pernambuco, situado na latitude de 58' 61" S, longitude 39' 89" W e altitude de 169 m, com temperatura média de $\pm 30,25^{\circ} \mathrm{C}$, umidade relativa do ar de $77,38 \%$, no período de janeiro a março de 2011 . O solo utilizado foi um Argissolo amarelo distrófico, de textura franco-arenosa, coletado no Município de Carpina, Pernambuco (Tabela 1).

Tabela 1. Características químicas do Argissolo Amarelo distrófico, coletado no Município de Carpina, Pernambuco

\begin{tabular}{ccc}
\hline Parâmetros & Unidade & Valores \\
$\mathrm{pH}$ (água) & - & 4,6 \\
$\mathrm{Ca}^{2+}$ & $\mathrm{cmol}_{\mathrm{c}} \mathrm{kg}^{-1}$ & 0,37 \\
$\mathrm{Mg}^{2+}$ & $\mathrm{cmol}_{\mathrm{c}} \mathrm{kg}^{-1}$ & 0,51 \\
$\mathrm{Na}^{+}$ & $\mathrm{cmol}_{\mathrm{c}} \mathrm{kg}^{-1}$ & 0,03 \\
$\mathrm{~K}^{+}$ & $\mathrm{cmol}_{\mathrm{c}} \mathrm{kg}^{-1}$ & 0,04 \\
$\mathrm{H}^{+}+\mathrm{Al}^{3+}$ & $\mathrm{cmol}_{\mathrm{c}} \mathrm{kg}^{-1}$ & 2,84 \\
$\mathrm{Al}^{3+}$ & $\mathrm{cmol}_{\mathrm{c}} \mathrm{kg}^{-1}$ & 0,91 \\
$\mathrm{~S}$ & $\mathrm{cmol}_{\mathrm{c}} \mathrm{kg}^{-1}$ & 0,95 \\
$\mathrm{~T}$ & $\mathrm{cmol}_{\mathrm{c}} \mathrm{kg}^{-1}$ & 4,70 \\
$\mathrm{C}$ & $\mathrm{g} \mathrm{kg}^{-1}$ & 7,0 \\
$\mathrm{~N}$ & $\mathrm{~g} \mathrm{~kg}^{-1}$ & 0,3 \\
$\mathrm{M} .0$. & $\mathrm{g} \mathrm{kg}^{-1}$ & 23 \\
$\mathrm{P}$ Assimilável & $\mathrm{mg} \mathrm{kg}^{-1}$ & 8 \\
$\mathrm{~K}$ & $\mathrm{mg} \mathrm{dm}^{-3}$ & 0,04 \\
\hline
\end{tabular}

Quanto à condução do experimento, o material de solo foi passado em peneira de $5 \mathrm{~mm}$ e autoclavado por 1 h e $30 \mathrm{~min}$, durante dois dias consecutivos, com intervalo de $24 \mathrm{~h}$, em temperatura de $120^{\circ} \mathrm{C}$ e pressão de $101 \mathrm{kPa}$ e acondicionado em vasos com 30,0 cm de altura e $17,0 \mathrm{~cm}$ de largura, com volume de $0,38 \mathrm{~m}^{3}$. Sementes de feijoeiro caupi cultivar EPACE-10 foram semeadas nos vasos os quais foram arranjados em delineamento em blocos ao acaso em esquema fatorial 2 (com e sem nematoide) $\times 2$ (com e sem estresse hídrico), com 6 repetições. A capacidade de pote (CP) foi adotada como o conteúdo de água no solo após sofrer saturação através da ação da gravidade, até o cessamento da drenagem, segundo Souza et al. (2000). O nível de estresse adotado foi de $50 \%$ da CP.

A irrigação dos vasos foi controlada através do procedimento de pesagem, os vasos foram pesados diariamente em balança de precisão com sensibilidade de $1 \mathrm{~g}$ entre 7 e 9 h da manhã, para posterior reposição da água evapotranspirada no período mantendo-se os vasos próximo à capacidade de campo. Já os vasos que receberam tratamento em condições de estresse hídrico recebiam apenas $50 \%$ da água evapotranspirada no mesmo período, iniciada no $10^{\circ}$ dia após a semeadura.

A população de M.incognita utilizada foi obtida no campo e propagada de progênies oriundas de uma massa de ovos, mantidas e multiplicadas em tomateiro (Solanum lycopersicum L. cultivar Santa Cruz) e em seguida em plantas de pimentão (Capsicum annuum L. cultivar All Big), em solo autoclavado. A obtenção do inóculo se fundamentou na metodologia descrita por Hussey \& Barker (1973) para extração de ovos, a partir das raízes parasitadas de plantas de pimentão. Os feijoeiros foram inoculados com 12.000 ovos planta $^{-1}, 15$ dias após a semeadura (quando iniciada a aplicação do estresse hídrico). A inoculação foi efetuada com pipeta de graduação automática e a suspensão 
de ovos vertida em orifícios efetuados ao redor da planta. Por ocasião da colheita, realizada 45 dias após a inoculação e tendo a cultura 55 dias, foram mensurados a altura da planta, o diâmetro do caule e a quantidade de folhas e determinados o índice de área foliar, o peso do material fresco das raízes, folhas e caule, o peso da matéria seca das folhas e caule, o número de galhas, o número de ovos por planta e o fator de reprodução do nematoide.

Para determinação do índice de área foliar as folhas recémcolhidas do feijoeiro foram digitalizadas com auxílio de um scanner e o cálculo realizado utilizando-se o programa Image (National Institute of Health, USA). As biomassas frescas (folhas e caule) foram colocadas em sacos de papel previamente identificados, pesadas, secadas em estufa com circulação de ar forçada a $65^{\circ} \mathrm{C}$ por $72 \mathrm{~h}$ ou até o peso constante e pesadas novamente com vista à determinação da matéria seca.

Para facilitar a remoção dos sistemas radiculares os vasos foram colocados em tanque de água por alguns minutos e os sistemas radiculares removidos cuidadosamente de modo a minimizar as perdas de massa de ovos do nematoide. Foram realizadas três lavagens de cada sistema radicular fazendo-o passar por baldes com água limpa; em seguida, foi determinado o peso da matéria fresca dos sistemas radiculares. Com auxílio de uma lupa foi realizada a contagem de galhas (Taylor \& Sasser, 1978) e as raízes cortadas em pequenos segmentos para extração dos ovos, conforme Hussey \& Barker (1973). O fator de reprodução (FR) foi calculado pela relação: $\mathrm{FR}=$ População final/População inicial. Foram consideradas resistentes as plantas que apresentaram FR $<1$ e susceptíveis as plantas com FR $>1$ (Cook \& Evans, 1987).

Para as análises bioquímicas foi utilizada a $3^{\circ}$ folha de cada planta, colocadas em nitrogênio líquido e acondicionas em freezer, a -3 a $-5{ }^{\circ} \mathrm{C}$, até o processamento. Os extratos das amostras foram preparados pela homogeneização de $0,1 \mathrm{~g}$ de matéria fresca em $4 \mathrm{~mL}$ do tampão fosfato de sódio $0,1 \mathrm{M}(\mathrm{pH}$ 6.5) adicionados de $0,05 \mathrm{~g}$ de polivinilpirrolidona (PVP). O homogenato foi centrifugado a $10.000 \mathrm{x} \mathrm{g} \mathrm{a} 4^{\circ} \mathrm{C}$, por $10 \mathrm{~min}$ (Zeraik et al., 2008) e realizada a análise das proteínas solúveis totais (Bradford, 1976) e das seguintes enzimas: catálase (Berrs \& Sizer, 1952), ascarbato peroxidase (Nakano \& Asada, 1981), polifenoloxidase (Kar \& Mishra, 1976) e peroxidase (Fatibelho Filho \& Vieira, 2002). Já para a análise do aminoácido prolina, foi preparado o extrato obtido de $0,1 \mathrm{~g}$ de matéria fresca em 5 $\mathrm{mL}$ de ácido sulfosalicílico a $3 \%$. O homogenato foi centrifugado por 10 min a $2.000 \mathrm{rpm}$ e filtrado em papel de filtro $\mathrm{n}^{\circ} 2$; em seguida, utilizou metodologia de Bates et al. (1973).

Os dados foram submetidos à análise de variância, com níveis de significância de 0,05 de probabilidade, pelo teste F. Quando significativas, as médias foram submetidas ao teste Tukey em nível de 0,05 de probabilidade utilizando-se o programa estatístico SAS.

\section{Resultados e Discussão}

Não houve interação entre os tratamentos com nematoide e estresse hídrico em relação à altura da planta, diâmetro do caule, número de folhas, índice de área foliar, número de ovos por planta, número de galhas e fator de reprodução e também não foi significativo o efeito isolado do estresse hídrico sobre essas variáveis exceto para o diâmetro do caule (Tabela 2) que apresentou maiores valores $(0,70 \mathrm{~mm})$ com $50 \%$ da capacidade do pote em contraste com $100 \%$ da capacidade do pote $(0,51$ $\mathrm{mm}$ ). Esses resultados corroboram com Mendes et al. (2007), que não observaram diferenças significativas no número de folhas produzidas nem no índice de área foliar do feijoeiro caupi cultivar EPACE 10, submetido a estresse hídrico na fase vegetativa (as plantas foram submetidas a ciclos de deficiência hídrica no $10^{\circ}$ ao $44^{\circ} \mathrm{DAS}$ ), constatando tolerância desta cultivar ao estresse hídrico.

Nascimento et al. (2004) relataram que os efeitos do déficit hídrico ocorridos na fase vegetativa do caupi cultivares EMAPA-821 e IPA 206, respectivamente, provocaram reduções nos componentes de crescimento em solo franco arenoso. Aguiar et al. (2008) afirmam que o feijoeiro não tem seu crescimento e produção afetados quando a água disponível no solo é mantida acima de 50\% da água disponível, já que mecanismos de escape e de tolerância são demandados para deficiências hídricas mais severas (Jongdee et al., 2006). Além disso, Guimarães et al. (2011) afirmam que o melhor estado hídrico pode estar associado tanto a mecanismo de contenção excessiva de perda de água como ao de melhor eficiência de absorção de água.

Em referência ao estresse promovido por $M$. incognita, a quantidade de ovos no final do experimento (9.898 ovos planta $^{-1}$ ) foi menor que o inoculado (12.000 ovos planta $\left.{ }^{-1}\right)$ resultando em fator de reprodução menor que $1(\mathrm{FR}=0,82)$, indicando resistência do cultivar EPACE 10 ao nematoide. Baida et al. (2011) observaram que cultivares de feijoeiro caupi e feijoeiro comum foram imunes a $M$. incognita, $M$. javanica, Heterodera glycines e $M$. paranaensis com FR igual a 0,16 , zero, 0,03 e 0,04 , respectivamente, representando resistência a nematoides de galhas, sendo uma opção de cultivo dessas leguminosas no semiárido do Nordeste já que é uma característica desejável em variedades e cultivares comerciais (Baida et al., 2011).

Estudando o comportamento de 20 cultivares de caupi em solo de textura arenosa, Goulart et al. (2004) observaram resistência

Tabela 2. Resumo de análises de variância das variáveis: altura da planta (ALT), diâmetro do caule (DIAM), número de folhas (NF), número de ovos por planta (OVOS), número de galhas (NG), fator de reprodução (FR) e índice de área foliar (IAF) do caupi parasitado por Meloidogyne incognita (12.000 ovos $\mathrm{mL}^{-1}$ planta $^{-1}$ ) sob estresse hídrico (50\% CP por 45 dias) em casa de vegetação

\begin{tabular}{|c|c|c|c|c|c|c|c|c|}
\hline \multirow{2}{*}{ Fonte de variação } & \multirow{2}{*}{ GL } & \multicolumn{7}{|c|}{ Quadrado médio } \\
\hline & & ALT & DIAM & NF & OVOS & NG & FR & IAF \\
\hline Estresse & 1 & $5,12^{\text {ns }}$ & $0,11^{\star}$ & $0,001^{\text {ns }}$ & $0,15^{\text {ns }}$ & $0,04^{\text {ns }}$ & $0,001^{\text {ns }}$ & $0,04^{\text {ns }}$ \\
\hline Nematóide & 1 & $7,72^{\text {ns }}$ & $0,003^{\text {ns }}$ & $0,19^{\text {ns }}$ & $92,54^{\star}$ & $12,17^{\star}$ & $4,65^{*}$ & $0,06^{\text {ns }}$ \\
\hline $\mathrm{E} \times \mathrm{N}$ & 1 & $3,24^{\mathrm{ns}}$ & $0,01^{\mathrm{ns}}$ & $0,06^{\text {ns }}$ & $0,003^{\text {ns }}$ & $0,002^{\text {ns }}$ & $0,006^{\text {ns }}$ & $0,02^{\text {ns }}$ \\
\hline Resíduo & 19 & 1,77 & 0,01 & 0,41 & 0,007 & 0,02 & 0,04 & 0,07 \\
\hline CV (\%) & - & 16,68 & 15,57 & 15,14 & 4,23 & 19,12 & 44,19 & 9,29 \\
\hline
\end{tabular}

*Significativo a nível de 0,05 de probabilidade; ns - Não significativo pelo teste $\mathrm{F}$ 
a M. incognita e $M$. javanica, embora tenha predominado reação de suscetibilidade. Silva et al. (2007) constataram, avaliando 40 genótipos inoculados com $M$. incognita raça 1 , também em solo arenoso, que embora 16 genótipos tenham sido classificados como resistentes, permitiram a reprodução do nematoide inviabilizando a utilização desses genótipos como fontes de resistência porém os autores afirmam que, tomando por base o sistema de produção do caupi, no qual existe um baixo grau de adoção tecnológica, a utilização de variedades resistentes desponta como alternativa viável para o manejo de nematoides das galhas.

Wanderley et al. (2007) apresentaram, contudo, resultados contrários a esta pesquisa. Trabalhando com sete cultivares de caupi inoculados com $M$. javanica esses pesquisadores verificaram que todos os cultivares avaliados foram suscetíveis ao nematoide, pois apresentaram valores de FR maiores que 1. Segundo os mesmos autores, a produção de sementes de caupi provenientes de plantas infectadas com $M$. javanica é possível mas, sem dúvida, esta produção será menor quando comparada a plantas não parasitadas; entretanto, se o produtor não puder substituir a cultura por outra ou se preferir continuar cultivando a mesma espécie numa área infestada, deverá optar por cultivares com menor suscetibilidade ou recorrer a plantas resistentes cultivadas em consórcio com outra planta não hospedeira.

Bitencourt \& Silva (2010) trabalharam com 24 genótipos de fava (Phaseolus lunatus L.) inoculados com duas espécies de Meloidogyne e verificaram resultados variados, não identificando material imune ou altamente resistente, embora três genótipos se tenham mostrado resistentes a $M$. incognita. Araújo Filho et al. (2010) verificaram que das 40 linhagens de feijão-guandu (Cajanus cajan (L) Hunth), apenas 11 se comportaram como resistentes $(\mathrm{FR}<1,0)$. Entre as linhagens resistentes duas (g5895 e g66-95) se destacaram por apresentar valores de FR muito próximos de zero corroborando Oliveira et al. (2012) que observaram que cinco genótipos de feijoeiro comum (CE-31, Frade Preto, CE-28, CE-01 e CE-315) foram altamente resistentes a $M$. incognita podendo representar mais uma alternativa ao produtor.

Não houve interação entre nematoide e estresse hídrico nem foi significativo o efeito isolado desses tratamentos em relação à biomassa fresca da raiz, biomassa fresca das folhas, biomassa fresca do caule, biomassa fresca total, biomassa seca das folhas, biomassa seca do caule e biomassa seca total das plantas (Tabela 3). Mendes et al. (2007) também não constataram efeito significativo do estresse hídrico aplicado na fase vegetativa na produção de matéria seca da parte aérea da cultivar EPACE 10 mas concluíram que apesar da tolerância a estiagens prolongadas o cultivar EPACE-10 é suscetível à falta de umidade durante a fase próxima à floração.

Ao estudar a cultura do caupi em diferentes fases fenológicas e diferentes níveis de disponibilidade de água no solo, Leite \& Virgens Filho (2004) relataram que, apesar da cultura ser afetada em alguns períodos de estresse, o caupi apresentou capacidade de suportar a baixa disponibilidade de água pois retomou, de forma lenta e contínua, o aumento da matéria seca em diversas partes da planta. Já Aguiar et al. (2008) relataram redução na matéria seca e no índice de área foliar quando quatro genótipos de feijoeiro comum (LP99-96, IPR UIAPURU, LP99-63 e IAPAR-81) foram submetidos ao estresse hídrico (cessamento da irrigação por 20 dias no início da floração) comprovando que a fase crítica do feijoeiro é a reprodutiva.

Não houve interação entre nematoide e estresse hídrico para catálase, peroxidase, ascarbato peroxidase, polifenoloxidase e prolina (Tabela 4); no entanto, nematoide e estresse hídrico interagiram afetando a atividade de proteína solúvel, o estresse hídrico afetou isoladamente a atividade de ascarbato peroxidase, polifenoloxidase e proteína solúvel no feijoeiro, enquanto o nematoide alterou a concentração de catálase e ascorbato peroxidase.

A enzima peroxidase apresentou variações quando a cultura do caupi foi submetida ao estresse hídrico (50\% CP); Santos et al. (2010) não obteveram diferença significativa, corroborando os resultados obtidos no presente estudo. Segundo Foyer \& Noctor (2003), as enzimas peroxidases estão ligadas ao diferentes mecanismos de

Tabela 3. Resumo de análises de variância das variáveis: biomassa fresca da raiz (BFR), biomassa fresca das folhas (BFF), biomassa fresca do caule (BFC), biomassa fresca total (BFT), biomassa seca das folhas (BSF), biomassa seca do caule (BSC) e biomassa seca total (BST) do caupi parasitado por Meloidogyne incognita (12.000 ovos mL ${ }^{-1}$ planta-1) sob estresse hídrico (50\% da capacidade do pote por 45 dias) em casa de vegetação

\begin{tabular}{cccccccccc}
\hline \multirow{2}{*}{ Fontes de variação } & GL & \multicolumn{7}{c}{ Quadrados médios } \\
\cline { 3 - 10 } Estresse & 1 & & BFR & BFF & BFC & BFT & BSF & BSC & BST \\
Nematóide & 1 & $0,07^{\text {ns }}$ & $0,07^{\text {ns }}$ & $0,002^{\text {ns }}$ & $0,03^{\text {ns }}$ & $0,05^{\text {ns }}$ & $0,08^{\text {ns }}$ & $0,17^{\text {ns }}$ \\
E $\times N$ & 1 & $0,001^{\text {ns }}$ & $0,05^{\text {ns }}$ & $0,02^{\text {ns }}$ & $0,02^{\text {ns }}$ & $0,05^{\text {ns }}$ & $0,25^{\text {ns }}$ & $0,27^{\text {ns }}$ & $0,56^{\text {ns }}$ \\
Resíduo & 19 & 0,07 & 0,07 & $0,02^{\text {ns }}$ & $0,004^{\text {ns }}$ & $0,01^{\text {ns }}$ & $0,02^{\text {ns }}$ \\
CV (\%) & & 26,94 & 19,79 & 13,18 & 14,05 & 23,09 & 20,15 & 0,35 \\
\hline
\end{tabular}

*Significativo a nível de 0,05 de probabilidade; ns - Não significativo pelo teste $\mathrm{F}$

Tabela 4. Resumo de análises de variância para catálase (CAT), peroxidase (POD), ascarbato peroxidase (APX), polifenoloxidas e (PPO), proteína solúvel (PS) e prolina (PRO) em feijoeiro caupi submetido ao parasitismo de Meloidogyne incognita (12.000 ovos $\mathrm{mL}^{-1}$ planta-1) sob estresse hídrico (50\% da capacidade do pote por 45 dias) em casa de vegetação

\begin{tabular}{|c|c|c|c|c|c|c|c|}
\hline \multirow{2}{*}{ Fonte de variação } & \multirow{2}{*}{ GL } & \multicolumn{6}{|c|}{ Quadrado médio } \\
\hline & & CAT & POD & APX & PPO & PS & PRO \\
\hline Estresse & 1 & $0,333^{\text {ns }}$ & $1802,5^{\text {ns }}$ & $55,59^{*}$ & $616,5^{\star}$ & $2,99^{*}$ & $0,001^{\text {ns }}$ \\
\hline Nematóide & 1 & $0,008^{\star}$ & $2370,8^{\text {ns }}$ & $2,66^{*}$ & $282,7^{\text {ns }}$ & $2,81^{\text {ns }}$ & $0,06^{\text {ns }}$ \\
\hline ExN & 1 & $0,465^{\text {ns }}$ & $90,3^{\text {ns }}$ & $43,06^{\text {ns }}$ & $93,4^{\mathrm{ns}}$ & $0,03^{*}$ & $0,01^{\text {ns }}$ \\
\hline Resíduo & 19 & 0,065 & 672,2 & 2,57 & 60,97 & 0,22 & 0,01 \\
\hline CV (\%) & & 18.75 & 12,25 & 17,95 & 13,59 & 12,88 & 12,27 \\
\hline
\end{tabular}

* Significativo a nível de 0,05 de probabilidade; ns - não significativo pelo teste $\mathrm{F}$ 
ajustes ao estresse. As atividades das enzimas polifenoloxidase e ascorbato peroxidase reduziram com a aplicação de estresse de $50 \%$ CP, independentemente de M. incognita (Tabela 5).

Campos et al. (2004) constataram que as enzimas oxidativas, como catálase, polifenoloxidase e ascorbato peroxidase,

Tabela 5. Valores médios da enzima polifenoloxidase (PPO) e ascorbato peroxidase (APX) em relação ao estresse hídrico (50\% da capacidade do pote) aplicado no feijoeiro caupi em casa de vegetação

\begin{tabular}{|c|c|c|}
\hline Estresse & $\begin{array}{c}\mathrm{PPO} \\
\left(\mathrm{mmol} \text { pirogalol } \mathrm{g}^{-1} \mathrm{MF} \mathrm{min}^{-1}\right)\end{array}$ & $\begin{array}{c}\text { APX } \\
\left(\mathrm{mg} \mathrm{H}_{2} \mathrm{O}_{2} \mathrm{~g}^{-1} \mathrm{MF} \mathrm{min}^{-1}\right)\end{array}$ \\
\hline Com (50\% CP) & $51,21 \mathrm{~b}$ & $51,99 \mathrm{~b}$ \\
\hline Sem $(100 \%$ CP) & $63,62 \mathrm{a}$ & $123,05 \mathrm{a}$ \\
\hline DMS & 8,50 & 33,39 \\
\hline
\end{tabular}

As letras diferentes na coluna apresentam médias diferentes significativamente pelo teste Tukey a nível de 0,05 de probabilidade.

CP - capacidade do pote, segundo Souza et al. (2000)

apresentam atividade enzimática alterada com o aumento do estresse abiótico. Algumas espécies de plantas são capazes de tolerar baixo teor de água nos tecidos das vegetais exibindo crescimento e manutenção dos processos metabólicos, mesmo em déficit hídrico celular (McCann \& Huang, 2008).

As atividades das enzimas polifenoloxidase e catálase reduziram com o parasitismo de M. incognita (Tabela 6).

Souza et al. (2004) relataram aumentos no conteúdo de prolina e açúcares solúveis totais em plantas de caupi em condições de estresse hídrico. Além disto, a atividade enzimática pode ser reduzida ou estimulada com estresse ambiental e algumas delas, como a peroxidase, podem ser mecanismos de defesa dos hospedeiros a patógenos (Rossiter et al., 2008). A exemplo, Oliveira et al. (2012) observaram que a atividade da enzima catálase foi alterada quando a variedade CE-109 estava parasitada com $M$. incognita.

A proteína solúvel aumentou 62,58\% quando submetida à aplicação de 50\% CP na presença de $M$. incognita (Tabela 7)

Tabela 6. Valores médios de ascorbato peroxidase (APX) e catálase (CAT) em feijoeiro caupi parasitado por $M$. incognita (12.000 ovos $\mathrm{mL}^{-1}$ planta-1) em casa de vegetação

\begin{tabular}{ccc}
\hline Nematoide & APX & CAT \\
Com & $\left(\mathbf{m m o l ~ H}_{2} \mathbf{O}_{2} \mathbf{~ g M F}^{-1} \mathbf{~ m i n}^{-1}\right)$ & $\left(\mathbf{m m o l ~ H}_{2} \mathbf{O}_{2} \mathbf{~ g}^{-1} \mathbf{M F} \mathbf{~ m i n}^{-1}\right)$ \\
Sem & $57,22 \mathrm{~b}$ & $0,29 \mathrm{~b}$ \\
DMS & $117,21 \mathrm{a}$ & $1,95 \mathrm{a}$ \\
\hline
\end{tabular}

As letras diferentes na coluna apresentam médias diferentes significativamente pelo teste Tukey a nível de 0,05 de probabilidade

CP - Capacidade do pote, segundo Souza et al. (2000)

Tabela 7. Valores médios da proteína solúvel (PS) da interação nematoide de galhas $M$. incognita (12.000 ovos $\mathrm{mL}^{-1}$ planta-1) $\times$ estresse hídrico $(50 \%$ da capacidade do pote por 45 dias) em feijoeiro caupi em casa de vegetação

\begin{tabular}{ccc}
\hline & \multicolumn{2}{c}{ PS (mg proteína solúvel $\mathbf{~ g}^{\mathbf{1}}$ MF) } \\
\cline { 2 - 3 } Estresse & \multicolumn{2}{c}{ Nematoide } \\
\cline { 2 - 3 } & Com & Sem \\
Com $(50 \% \mathrm{CP})$ & $20,07 \mathrm{aA}$ & $12,76 \mathrm{aB}$ \\
Sem $(100 \% \mathrm{CP})$ & $7,51 \mathrm{bB}$ & $12,71 \mathrm{aB}$ \\
DMS & & 5,28 \\
\hline
\end{tabular}

Letras diferentes apresentam médias diferencas significativamente para cada variável pelo teste Tukey a nível de 0,05 de probabilidade, sendo que letras minúsculas refere-se à linha e letras maiúsculas refere-se à coluna

CP - capacidade do pote, segundo Souza et al. (2000) atribuindo este comportamento ao evento da falta de água ter aumentado a atividade do teor de proteínas solúveis nas folhas da cultura do feijão caupi cv. EPACE-10.

Resultado semelhante foi descrito por Santos et al. (2010) que observaram efeito não significativo nos teores de açúcares em oito cultivares de caupi quando submetidos a estresse hídrico na prefloração apesar de apresentarem variações na atividade enzimática ocorrendo diminuição em condições de estresse hídrico.

\section{Conclusões}

1. O desenvolvimento do cultivar EPACE-10 de feijoeiro caupi não é afetado por um nível de estresse hídrico equivalente a $50 \%$ da capacidade do pote;

2. A peroxidase não foi afetada, porém a catálase foi diminuída pelo parasitismo do nematoide; já a ascorbato peroxidade foi diminuída pelo estresse hídrico e a polifenoloxidase foi diminuída tanto pelo estresse hídrico como pelo parasitismo de M. incognita.

\section{Agradecimentos}

À FACEPE, pelo financiamento da pesquisa.

\section{Literatura Citada}

Aguiar, R. S. de; Cirino, V. M.; Faria, R. T.; Vidal, L. H. I. Avaliação de linhagens promissoras de feijoeiro (Phaseolos vulgaris $\mathrm{L}$.) tolerantes ao déficit hídrico. Ciências Agrárias, v.29, p.1-14, 2008. http:// dx.doi.org/10.5433/1679-0359.2008v29n1p1

Araújo Filho, J. V.; Inomoto, M. M.; Godoy, R.; Ferraz, L. C. C. B. Resistência de linhagens de feijão-guandu a Meloidogyne javanica. Nematologia Brasileira, v.34, p.75-81, 2010.

Baida, F. C.; Santiago, D. C.; Takahashi, L. S. A.; Athanazio, J. C.; Cadioli, M. C.; Levy, R. M. Reações de linhagem de feijão-vagem ao Meloidogyne javanica e M. paranaensis em casa-de-vegetação. Acta Scientiarum Agronomy, v.33, p.237-341, 2011. http://dx.doi. org/10.4025/actasciagron.v33i2.6146

Bates, L. S.; Waltren, R. B.; Teare, I. D. Rapid determination of free praline for water- estress studis. Plant and Soil, v.39, p.205-207, 1973. http://dx.doi.org/10.1007/BF00018060

Berrs, L. S. J.; Sizer, I. W.A. espectrophotometric method for measuring the breakdown of hydrogen peroxide by catalase. Journal of Biological Chemistry, v.195, p.133-140, 1952.

Bitencourrt, N. V:; Silva, G. S. Reação de genótipos de fava a Meloidogyne incognita e M. enterolobii. Nematologia Brasileira, v.34, p.184-186, 2010.

Bradford, M. M. A rapid and sensitive method for the quantification of microgram quantities of protein utilizing the principles of proteindye binding. Analytical Biochemistry, v.72, p.248-254, 1976. http:// dx.doi.org/10.1016/0003-2697(76)90527-3

Campos, A. D.; Ferreira, A. G.; Hampe, M. M. V.; Antunes, I. F.; Brancão, N.; Silveira, E. P. da; Osório, V. A.; Augustin, E. Atividade de peroxidase e polifenoloxidase na resistência do feijão à antracnose. Pesquisa Agropecuária Brasileira, v.39, p.637-643, 2004. http:// dx.doi.org/10.1590/S0100-204X2004000700004

Cook, R.; Evans, K. Resistance and tolerance. In: Brown, R. H.; Kerry, B. R. (ed.). Principles and practice of nematode control in crops. New York: Academic Press, 1987. p.179-231. 
Fatibelho Filho, O.; Vieira, I. C. Uso analítico de tecidos e de extratos brutos vegetais como fonte enzimática. Química Nova, v.25, p.455464, 2002. http://dx.doi.org/10.1590/S0100-40422002000300019

Foyer, C. H.; Noctor, G. Redox sensing and signalling associated with reactive oxygen in chloroplasts, peroxisomes and mitochondria. Physiologia Plantarum, v.119, p.355-364, 2003. http://dx.doi. org/10.1034/j.1399-3054.2003.00223.x

Goulart, R. dos R.; Nascimento, R. R. S. do; Nascimento, R. J. do; Santos, C. L. R. dos; Silva, P. C. P. da; Gavazza, M. I. A.; Pimentel, J. P. Avaliação de linhagens e cultivares de caupi à infecção por Meloidogyne incognita e M. javanica. Agronomia, v.38, p.51-54, 2004.

Guimarães, C. M.; Stone, L. F.; Peloso, M. J. D.; Oliveira, J. P. de. Genótipos de feijoeiro comum sob deficiência hídrica. Revista Brasileira de Engenharia Agrícola e Ambiental, v.15, p.649-656, 2011. http://dx.doi.org/10.1590/S1415-43662011000700001

Hussey, R. S.; Barker, K. R.A comparison of methods of collecting inocula for Meloidogyne spp., including a new technique. Plant Disease Reporter, v.57, p.1025-1028, 1973.

Jongdee, B.; Pantuwan, G.; Fukai, S.; Fischer, K. Improving drought tolerance in rainfed lowland rice: An example from Thailand. Agricultural Water Management, v.80, p.225-240, 2006. http:// dx.doi.org/10.1016/j.agwat.2005.07.015

Kar, M.; Mishra, D. Catalase, peroxidase and poliphenoloxidase activities during rice leaf senescence. Plant Physiology, v.57, p.315319, 1976. http://dx.doi.org/10.1104/pp.57.2.315

Leite, M. de L.; Virgens Filho, J. S. das. Produção de matéria seca em plantas de caupi (Vigna unguiculata (L.) Walp) submetida a déficit hídrico. Ciências Exatas e da Terra, v.10, p.43-51, 2004.

McCann, S. E.; Huang, B. Evaluation of drought tolerance and avoidance traits for six creeping bentgrass cultivars. Horticultural Science, v.43, p.519-524, 2008.

Mendes, R. M. de S.; Távora, F. J. A. F.; Pitombeira, J. B.; Nogueira, R. J. Relações fonte-dreno em feijão-de-corda submetido à deficiência hídrica. Revista Ciência Agronômica, v.38, p.95-103, 2007.

Nakano, Y.; Asada, K. Hydrogen peroxide is scavenged by ascorbatespecific peroxidase in spinach chloroplasts. Plant Cell Physiology, v.22, p.867-880, 1981.

Nascimento, J. T.; Pedrosa, M. B.; Tavares Sobrinho, J. Efeito da variação de níveis de água disponível no solo sobre o crescimento e produção do feijão caupi, vagens e grãos verdes. Horticultura Brasileira. v.22, p.174-177, 2004. http://dx.doi.org/10.1590/S010205362004000200002
Oliveira, J. T. A.; Andrade, N. C.; Miranda, A. S. M.; Soares, A. A.; Gondim, D. M. F.; Araújo Filho, J. H.; Freire Filho, F. R.; Vasconcelos, I. M. Differential expression of antioxidant enzymes and PR-proteins in compatible and incompatible interactions of cowpea (Vigna unguiculata) and the root-knot nematode Meloidogyne incognita. Plant Physiology and Biochemistry, v.51, p.145-152, 2012. http://dx.doi.org/10.1016/j.plaphy.2011.10.008

Rossiter, J. G. de A.; Musser, R. dos S.; Martins, L. S. S.; Pedrosa, E. M. R.; Medeiros, J. M. de. Seleção de genótipos de aceloleira assistida por marcadores isoenzimáticos visando à resistência a Meloidogyne incognita raça 2. Revista Brasileira de Fruticultura, v.30, p. 1057-1064, 2008. http://dx.doi.org/10.1590/S010029452008000400036

Santos, C. F.; Lima, G. P. P.; Morgado, L. B. Tolerância e caracterização bioquímica em feijão caupi submetido a estresse hídrico na préfloração. Naturalia, v.33, p.34-44, 2010.

Silva, G. S.; Freire Filho, F. R.; Pereira, A. L.; Silva, C. L. Reação dos genótipos de feijão caupi a Meloidogyne incognita raça 1. Nematologia Brasileira. v.31, p.1-3, 2007.

Souza, C. C. de; Oliveira, F. A.; Silva, I. F.; Amorim Neto, M. S. Avaliação de métodos de determinação de água disponível e manejo da irrigação em terra roxa sob cultivo de algodoeiro herbáceo. Revista Brasileira de Engenharia Agrícola e Ambiental, v.4, p.338-342, 2000. http://dx.doi.org/10.1590/S1415-43662000000300006

Souza, R. P.; Machado, E. C.; Silva, J. A. B.; Lagoa, A. M. M. A.; Silveira, J. A. G. Photosynthetic gas exchange, chlorophyll fluorescence and some associate metabolic changes in cowpea (Vigna unguiculata) during water stresss and relovery. Environmental and Experimental Botany, v.51, p.45-56, 2004. http://dx.doi.org/10.1016/S00988472(03)00059-5

Taylor, A. L.; Sasser, J. N. Biology, Identification and control of rootknot nematodes (Meloidogyne species). Raleigh: North Carolina State University, 1978. 111p.

Wanderley, M. J. A.; Wanderley, P. A.; Athayde Filho, P. F. de; Santos, J. M. dos; Pereira, E. R. Resistência genética do feijão caupi ao nematoide Meloidogyne javanica. Revista Brasileira Agroecologia, v.2, p.1377-1380, 2007.

Zeraik, A. E.; Souza, F. S. de; Fatibello Filho, O.; Leite, O. D. Desenvolvimento de um spot test para o monitoramento da atividade da peroxidase em um procedimento de purificação. Química Nova, v.31, p.731-734, 2008. http://dx.doi.org/10.1590/ S0100-40422008000400003 